\title{
Effect of water activity on the thermal inactivation kinetics of Salmonella in milk powders
}

\author{
Xinyao Wei, ${ }^{1} \odot$ Soon Kiat Lau, ${ }^{1,2} \odot$ Byron D. Chaves, ${ }^{1}$ Mary-Grace C. Danao, ${ }^{1,3} \odot$ Shantanu Agarwal, ${ }^{4}$ \\ and Jeyamkondan Subbiah ${ }^{5 *}$ (i) \\ ${ }^{1}$ Department of Food Science and Technology, University of Nebraska, Lincoln 68588 \\ ${ }^{2}$ Department of Biological Systems Engineering, University of Nebraska-Lincoln, Lincoln 68583 \\ ${ }^{3}$ The Food Processing Center, University of Nebraska, Lincoln 68588 \\ ${ }^{4}$ Mars Wrigley Confectionery, Chicago, IL 60560 \\ ${ }^{5}$ Department of Food Science and Technology, University of Arkansas, Fayetteville 72704
}

\begin{abstract}
Persistence of Salmonella in milk powders has caused several foodborne outbreaks. The determination of proper pasteurization processing conditions requires an understanding of the thermal inactivation kinetics of Salmonella in milk powders. However, there is a lack of knowledge related to the effects of water activity $\left(\mathrm{a}_{\mathrm{w}}\right)$ and fat content on Salmonella inactivation in milk powder during thermal processing. Two types of milk powders, nonfat dry milk and whole milk powder, with different fat contents (0.62 and $29.46 \%$ wt/wt, respectively) were inoculated with a 5-strain cocktail of Salmonella and equilibrated to $3 \mathrm{a}_{\mathrm{w}}$ levels $(0.10,0.20$, and 0.30 ) for isothermal treatments at 75,80 , and $85^{\circ} \mathrm{C}$ to obtain $D$-values (the time required to achieve a 10 -fold reduction of the bacteria at the isothermal treatment temperature) and $z$-values (the increase in temperature required to achieve a $90 \%$ reduction of the decimal reduction time $D$ ). Stability tests showed that the inoculation method used in this study provided a high and stable population of Salmonella for thermal inactivation studies. A moisture sorption isotherm was measured to understand the relationship between $\mathrm{a}_{\mathrm{w}}$ and moisture content of milk powders. The thermal resistance of Salmonella was found to significantly increase as $\mathrm{a}_{\mathrm{w}}$ decreased, which suggested that a higher temperature or longer processing time would be required at low $\mathrm{a}_{\mathrm{w}}$ to achieve the desired inactivation of Salmonella. The microbial inactivation kinetics were not significantly different for the 2 milk powders; therefore, data were combined to develop a universal model. A response surface model was compared with a modified Bigelow model. The modified Bigelow model performed well to predict $D$-values [root mean square error (RMSE) $=$
\end{abstract}

Received January 31, 2020.

Accepted March 22, 2020.

*Corresponding author: jsubbiah@uark.edu
$1.47 \mathrm{~min}]$ and $\log$ reductions $(\mathrm{RMSE}=0.48 \mathrm{log} \mathrm{cfu} / \mathrm{g})$. The modified Bigelow model developed here could be used to estimate $D$-value as a function of water activity and temperature to design a thermal pasteurization system for milk powders.

Key words: heat resistance, dry milk powder, moisture sorption isotherm, low-moisture food

\section{INTRODUCTION}

Annually, nontyphoidal Salmonella causes approximately 1.2 million illnesses and 450 deaths in the United States (Johnson et al., 2014). Historically, several foodborne illness outbreaks have been caused by Salmonella-contaminated milk powders, such as powdered infant formula (Rowe et al., 1987; Park et al., 2004; Brouard et al., 2007; Angulo et al., 2008; Rodríguez-Urrego et al., 2010), powdered milk products (CDC, 1993), infant milk powders (Jourdan-da Silva et al., 2018), skim milk powder, and dry milk powder (el-Gazzar and Marth, 1992). Milk powders are produced by spray drying of liquid milk. Although spray drying reduces the total bacterial population, it is not a pasteurization process, and Salmonella may remain viable after the process (LiCari and Potter, 1970). Additionally, after spray drying, opportunities exist for milk powders to be crosscontaminated, including poor environmental sanitation practices and inadequate storage conditions (Podolak et al., 2010). Currently, no processing step follows spray drying to pasteurize milk powders (LiCari and Potter, 1970). Considering that milk powders are commonly used as ingredients in many ready-to-eat foods (that do not undergo further cooking steps before consumption), such as confectionery, drink mixes, seasoning, nutritional bars, and dry blend infant formula, , it is therefore necessary to identify an effective pasteurization process to improve the food safety of milk powders (Reij and Den Aantrekker, 2004).

Milk powders are considered low-water-activity $\left(\mathbf{a}_{\mathrm{w}}\right)$ foods, with typical $\mathrm{a}_{\mathrm{w}}$ values $<0.70$, at which Salmo- 
nella is unable to multiply (Blessington et al., 2013). Although milk powders do not support the growth of Salmonella, higher survival of Salmonella is observed with declining $\mathrm{a}_{\mathrm{w}}$ (Lian et al., 2015). However, Salmonella has been shown to survive for a long period in low- $\mathrm{a}_{\mathrm{w}}$ food commodities (Keller et al., 2013; Tsai et al., 2019). Furthermore, Salmonella may possess higher thermal resistance with decreasing $\mathrm{a}_{\mathrm{w}}$ (Villa-Rojas et al., 2013; Smith et al., 2016; Syamaladevi et al., 2016).

The enhanced heat resistance of Salmonella at lower $\mathrm{a}_{\mathrm{w}}$ makes the elimination of Salmonella in milk powders a serious challenge for the food industry. Unlike pasteurization of high- $a_{w}$ foods, the thermal processing of low- $\mathrm{a}_{\mathrm{w}}$ food is a dynamic process. As moisture evaporates during the thermal process, $\mathrm{a}_{\mathrm{w}}$ is expected to decrease, which could affect inactivation of Salmonella because of its enhanced heat resistance at reduced $\mathrm{a}_{\mathrm{w}}$. To account for this dynamic thermal resistance during thermal pasteurization, the effect of $\mathrm{a}_{\mathrm{w}}$ on Salmonella inactivation in milk powders needs to be evaluated. In the dairy industry, the moisture contents of milk powders are monitored as part of the process controls (Hutson, 2017). Therefore, the development of moisture sorption isotherms of milk powder will be helpful to clarify the relationship between $\mathrm{a}_{\mathrm{w}}$ and moisture content and subsequently link moisture content to the inactivation of Salmonella. Additionally, the different fat and carbohydrate contents of different types of milk powders could contribute to the variation in bacterial inactivation in milk powders. Relatively high fat content has been shown to have a protective effect on Salmonella during thermal processing (Ahmed et al., 1995; Verma et al., 2018). Thus, it is also important to evaluate the effect of fat content on the microbial inactivation kinetics of Salmonella in milk powders. A better understanding of the thermal inactivation kinetics of Salmonella in milk powders will be helpful to guide the dairy industry in designing thermal pasteurization processes for milk powders.

The objectives of this study were to (1) determine the moisture sorption isotherm of milk powders; (2) evaluate the effect of $\mathrm{a}_{\mathrm{w}}$ on microbial inactivation kinetics of Salmonella in milk powders; and (3) assess the effect of fat content on microbial inactivation kinetics.

\section{MATERIALS AND METHODS}

\section{Milk Powder Samples}

For this study, 3 production batches of 2 different milk powders, grade A pasteurized nonfat dry milk (NFDM) and grade A pasteurized whole milk powder (WMP) were provided by Mars Inc. (McLean, VA). Upon receiving the samples, total plate counts were performed to quantify the background microflora in milk powders following standard procedures (VillaRojas et al., 2017; Liu et al., 2018). Three random 10-g samples were removed from each batch and diluted in $90 \mathrm{~mL}$ of $0.1 \%$ buffered peptone water (BPW; Becton, Dickinson and Co., Sparks, MD). The diluted samples were blended for $1 \mathrm{~min}$ in a paddle mixer (Neutec Group Inc., Farmingdale, NY), serially diluted in 9 $\mathrm{mL}$ of $0.1 \%$ BPW blanks, plated onto tryptic soy agar (TSA) supplemented with $0.6 \%$ (wt/vol) yeast extract (TSAYE), and incubated for $24 \mathrm{~h}$ at $37^{\circ} \mathrm{C}$ for enumeration.

\section{Proximate Composition and Calorie Estimation}

Official methods (AOAC International, 2000) were used to determine ash (method 985.01), fat (method 989.05), and protein (method 990.03) of NFDM and WMP. The moisture contents of both milk powders were measured by a halogen moisture analyzer (HR73, Mettler Toledo Laboratory and Weighing Technologies, Greifensee, Switzerland), and $\mathrm{a}_{\mathrm{w}}$ values at $25^{\circ} \mathrm{C}$ were determined with a dew point water activity meter (Aqualab Series 4TE, Meter Group, Pullman, WA). Carbohydrates were determined by subtracting other compositions from the total weight. Calories were calculated using the Atwater general factors, which are $4 \mathrm{kcal} / \mathrm{g}$ for protein, $9 \mathrm{kcal} / \mathrm{g}$ for fat, and $4 \mathrm{kcal} / \mathrm{g}$ for carbohydrate.

\section{Moisture Sorption Isotherm}

The moisture sorption isotherm of each milk powder product was generated with an AquaLab Vapor Sorption Analyzer (Meter Group Inc.) at $20^{\circ} \mathrm{C}$. Approximately $1 \mathrm{~g}$ of sample was spread uniformly on a stainless steel sample cup for measurement of both absorption and desorption curve at a single temperature. the dynamic vapor sorption method was used to measure the sorption isotherm (Garbalińska et al., 2017). For the sorption isotherm development, the moisture content at equilibrated points was determined in triplicate at $\mathrm{a}_{\mathrm{w}}$ levels from 0.10 to 0.90 with 0.05 intervals. The trigger (\% $\mathrm{d} m / \mathrm{d} t$; percent change in mass over a change in time for determination of the equilibrated point) was set at $0.020 \% / \mathrm{h}$ with 3 events, which indicated that 3 readings in a row must be less than the set trigger value.

\section{Bacterial Strain and Inoculation}

The 5 strains of Salmonella enterica used in this study have been associated with different low $a_{w}$ foodborne outbreaks. Salmonella enterica subsp. enterica serovar 
Agona 447967, Salmonella Montevideo 488275, and Salmonella Mbandaka 698538 were obtained from the Food and Drug Administration( Office of Regulatory Affairs Regional Laboratory, Jefferson, AR). Salmonella Reading 180418 and Salmonella Tennessee K4643 were obtained from the University of Georgia (Athens). The frozen bacteria cultures were kept in trypticase soy broth (TSB) with $0.6 \%$ (wt/vol) yeast extract (TSBYE) supplemented with $20 \%$ glycerol and stored at $-80^{\circ} \mathrm{C}$ until used.

Procedures to prepare the Salmonella inoculum were similar to those described in Hildebrandt et al. (2016) and Liu et al. (2018). To prepare the 5-strain Salmonella cocktail, one cryovial of frozen culture of each Salmonella strain was thawed at $22^{\circ} \mathrm{C}$ for $10 \mathrm{~min}$. Then, $1 \mathrm{~mL}$ of each bacterial culture was transferred to $10 \mathrm{~mL}$ of TSBYE and incubated for $24 \pm 2 \mathrm{~h}$ at $37^{\circ} \mathrm{C}$. From the overnight culture, 1 loopful of culture was streaked onto the surface of TSAYE. After incubation at $37^{\circ} \mathrm{C}$ for $24 \pm 2 \mathrm{~h}$, the agar plate with isolated colonies was wrapped with parafilm and stored at $4^{\circ} \mathrm{C}$ for up to 1 mo. One isolated colony of each strain was transferred to $10 \mathrm{~mL}$ of TSBYE and incubated for $24 \mathrm{~h}$ at $37^{\circ} \mathrm{C}$ for a second enrichment. To prepare the inoculum lawn, $0.1 \mathrm{~mL}$ of the overnight culture was spread plated onto TSAYE plates for incubation $\left(24 \pm 2 \mathrm{~h}\right.$ at $\left.37^{\circ} \mathrm{C}\right)$. The overnight lawns grown on the plate were harvested by adding $3 \mathrm{~mL}$ of $0.1 \% \mathrm{BPW}$ and agitating the lawns with a sterile L-shaped spreader. Equal amounts of the dissolved lawns of each Salmonella strain were transferred to a sterile centrifuge tube and vortexed for $10 \mathrm{~s}$ to prepare the Salmonella cocktail. The initial bacterial population of the Salmonella cocktail was approximately $10.5 \log \mathrm{cfu} / \mathrm{mL}$.

The prepared Salmonella cocktail $(10 \mathrm{~mL})$ was sprayed onto $100 \pm 0.1 \mathrm{~g}$ of WMP or NFDM samples in a sterile Whirl-Pak bag $(23 \times 12 \mathrm{~cm}$; Whirl-Pak, Nasco, Fort Atkinson, WI). The inoculated sample was hand-massaged to exfoliate all powder from the inner surface of the bag and then the sample was homogenized in a paddle mixer for 6 min.

\section{Sample Equilibration and Stability Tests}

Inoculated samples were placed uniformly on a sanitized aluminum tray $(230 \times 300 \times 15 \mathrm{~mm})$ and transferred to a custom-designed humidity-controlled chamber. To evaluate the effect of $\mathrm{a}_{\mathrm{w}}$ on thermal inactivation of Salmonella, the relative humidity in the chamber was set to $10.0,20.0$, or $30.0 \%$ to equilibrate the inoculated sample to a target $\mathrm{a}_{\mathrm{w}}$ of $0.10,0.20$, and 0.30 , respectively. During the inoculation process, the addition of moisture from the inoculum caused the powders to cake and form clumps; therefore, additional steps were taken to reduce the clumps back into powder. Upon reaching the target $\mathrm{a}_{\mathrm{w}}$, inoculated samples were packed into sterile Whirl-Pak bags and homogenized in a paddle mixer for 3 min to break the dried-up clumps. The homogenized samples were transferred back to the humidity-controlled chamber for re-equilibration.

Stability tests were conducted for both powder samples at an $\mathrm{a}_{\mathrm{w}}$ of 0.20 to evaluate the inoculation method used in this study. At d 0, 1, 2, 3, 4, 5, 8, 12, 16 , and $20,2 \pm 0.1 \mathrm{~g}$ of each inoculated powder sample from each batch were transferred to a sterile Whirl-Pak bag for enumeration. The samples were first diluted 10 -fold with $18 \mathrm{~mL}$ of $0.1 \% \mathrm{BPW}$ and then stomached for $1 \mathrm{~min}$. Blended samples were serially diluted in 9 $\mathrm{mL}$ of $0.1 \%$ BPW and 3 dilutions of all samples were plated in duplicate onto TSAYE supplemented with $0.05 \%$ (wt/vol) ammonium iron citrate (Sigma-Aldrich Co., St. Louis, MO), and $0.03 \%$ (wt/vol) sodium thiosulfate (mTSA; Fisher Chemical, Lenexa, KS) and incubated for $24 \mathrm{~h}$ at $37^{\circ} \mathrm{C}$ (Smith et al., 2016; Liu et al., 2019). After incubation, colonies with a black center were enumerated as Salmonella. Homogeneity of inoculated samples was evaluated by counting colonies on 6 randomly selected subsamples $(2 \pm 0.1 \mathrm{~g})$ from a $100-\mathrm{g}$ batch of inoculated powder on d 1. Inoculated samples were considered to be homogeneous when the standard deviation of the 6 enumerated samples was $<0.3 \log \mathrm{cfu} / \mathrm{g}$.

\section{Isothermal Inactivation}

In this study, we conducted the isothermal treatment of inoculated milk powder using a custom-designed thermal-death-time sandwich (Lau et al., 2019). Two grams of inoculated sample was packed into an aluminum-laminated plastic pouch $(75 \times 75 \times 1 \mathrm{~mm}$, Impak Corp., Los Angeles, CA). To measure the temperature of the sample, a T-type thermocouple probe was inserted into the center of the aluminum pouch. The come-up time at each temperature was defined as the time required for the sample temperature from room temperature $\left(22^{\circ} \mathrm{C}\right)$ to reach $0.5^{\circ} \mathrm{C}$ below the target temperature. For each target temperature, the average of 3 measurements of come-up time plus 2 standard deviations was used as time zero for the subsequent isothermal treatment. No thermocouples were inserted into the inoculated samples during the actual isothermal treatments.

The isothermal treatment temperatures used to obtain thermal death curves for Salmonella in both WMP and NFDM were 75,80 , and $85^{\circ} \mathrm{C}$. The target isothermal temperatures were determined based on our preliminary experiments. Temperatures $>85^{\circ} \mathrm{C}$ can result in discoloration of samples, and temperatures $<75^{\circ} \mathrm{C}$ 
result in a long pasteurization time. Six time points, including time zero, with equal time intervals were used for isothermal treatment to achieve at least a 3-log reduction of Salmonella. After each isothermal treatment, the treated aluminum pouch was immediately transferred to an ice-water bath for about 1 min to stop further thermal inactivation. The treated samples were enumerated using the same method as described previously in the sample equilibration and stability tests section. Three biological replicates (batches of milk powder samples from different production lots inoculated with independently grown bacterial cultures) were used in the experiments. Untreated inoculated samples from each batch were randomly selected and enumerated as the control.

\section{Determination of $D$ - and z-Values}

The thermal inactivation kinetics of Salmonella in milk powders were modeled with the log-linear model to obtain the $D$-value:

$$
D=\frac{t}{\log _{10} N_{0}-\log _{10} N},
$$

where $N_{0}(\mathrm{cfu} / \mathrm{g})$ is the bacteria population at come-up time, $N(\mathrm{cfu} / \mathrm{g})$ is the bacteria population at time $t$, $t$ (min) is the length of isothermal treatment, and $D$ (min) is the time required to achieve a 10-fold (decimal) reduction of the bacteria at the isothermal treatment temperature. In addition to $\mathrm{R}^{2}$ values, the goodnessof-fit of the models were quantified by the root mean square error (RMSE; log cfu/g):

$$
R M S E=\sqrt{\frac{\sum_{i=1}^{n}\left[\log _{10}(N)_{\text {observed, } i}-\log _{10}(N)_{\text {predicted }, i}\right]^{2}}{n}},
$$

where $\log _{10}(N)_{\text {observed,i }}$ is the observed log population, $\log _{10}(N)_{\text {predicted, } i}$ is the predicted log population from the model, and $n$ is the total number of observations.

The $z$-value is defined as the increase in temperature required to achieve a $90 \%$ reduction of the decimal reduction time $D$ and was determined as follows:

$$
z=\frac{T_{2}-T_{1}}{\log _{10} D_{T_{1}}-\log _{10} D_{T_{2}}},
$$

where $D_{T_{1}}$ and $D_{T_{2}}$ are the $D$-values at temperatures $T_{1}$ and $T_{2}$, respectively.

\section{Secondary Model Fitting}

A split-plot analysis (where $\mathrm{a}_{\mathrm{w}}$ is the whole plot and temperature is the subplot) was used to determine the effect of temperature and $\mathrm{a}_{\mathrm{w}}$ on the $D$-value and reduction of Salmonella in WMP and NFDM. The first secondary model evaluated in this study was a response surface model (RSM), and only factors with significant effects $(P<0.05)$ were considered. The parameters for the RSM were estimated using ANOVA and response surface method functions in the open-source statistical software R (https://www.R-project.org/; Lenth, 2009).

The second secondary model evaluated in this study was a modified version of a Bigelow-type relationship (Gaillard et al., 1998):

$$
D\left(T, a_{w}\right)=D_{r e f} \cdot 10^{\frac{a_{w, r e f}-a_{w}}{z_{a_{w}}}} \cdot 10^{\frac{T_{r e f}-T}{z_{T}}},
$$

where $D_{\text {ref }}$ is the time (min) needed to achieve a 10-fold reduction in the population at $T_{r e f}$ and $a_{w, r e f}, T$ is the temperature $\left({ }^{\circ} \mathrm{C}\right), T_{\text {ref }}$ and $a_{w, r e f}$ are the optimized reference temperature and water activity (Dolan et al., 2013), and $z_{a_{w}}$ or $z_{T}$ is the $\mathrm{a}_{\mathrm{w}}$ or temperature increment needed to decrease the $D$-value by 10 -fold, respectively. All parameters for the Bigelow-type model were estimated using ordinary least squares (OLS) minimization with nlinfit in MATLAB 2019 (MathWorks, Natick, MA).

The corrected Akaike information criterion $\left(\mathbf{A I C}_{\mathbf{c}}\right)$ was calculated to evaluate each model (Motulsky and Christopoulos, 2004):

$$
\mathrm{AIC}_{\mathrm{c}}=\operatorname{nln}\left(\frac{S S}{n}\right)+2 K+\frac{2 K(K+1)}{n-K-1},
$$

where $n$ is the total number of the data points, $S S$ is the sum of squares of the residuals, and $K$ is the number of parameters being estimated plus 1 . Lower $\mathrm{AIC}_{\mathrm{c}}$ values indicate that the determined model is more likely to be correct for the data.

\section{RESULTS AND DISCUSSION}

\section{Moisture Sorption Isotherm}

The moisture sorption isotherm results are shown in Figure 1. For both milk powders, the moisture contents slowly increased with increasing $\mathrm{a}_{\mathrm{w}}$. After $\mathrm{a}_{\mathrm{w}}$ reached 0.40 , the moisture content was found to increase sharply with increasing $\mathrm{a}_{\mathrm{w}}$ until it reached 0.55 , which may 
be attributed to capillary condensation (Tham et al., 2016). When the powder started to absorb moisture, part of the powder became crystalline and part of it remained amorphous. Compared with the corresponding pure amorphous substance, powders containing a mixture of amorphous and crystalline components have greater water sorption capacity (Hartmann and Palzer, 2011). Consequently, a higher absorption rate of moisture was observed after the initial uptake of moisture.

After $\mathrm{a}_{\mathrm{w}}$ reached 0.60 , the moisture contents of both milk powders declined slightly, which may be due to lactose crystallization (Tham et al., 2016). According to McCarthy et al. (2013), a sudden decrease in water content is observed because the amorphous lactose has lower water sorption before lactose crystallization. Subsequent increases in $\mathrm{a}_{\mathrm{w}}$ are followed by an increase in the moisture content. At high $\mathrm{a}_{\mathrm{w}}$, lactose crystallization is an irreversible change (Berggren and Alderborn, 2004); therefore, the trends observed from 0.4 to $0.6 \mathrm{a}_{\mathrm{w}}$ in the absorption curve were not observed in the desorption curve. At the same $a_{w}$ level, NFDM had a higher moisture content than WMP (Figure 1), which was due to the higher protein content of NFDM (Table 1). Proteins have been shown to increase moisture absorption in milk powder, by binding more water molecules at the same $\mathrm{a}_{\mathrm{w}}$ level (Ibach and Kind, 2007; Shrestha et al., 2007). Therefore, NFDM was found to have higher moisture content than WMP at the same $\mathrm{a}_{\mathrm{w}}$ level due to interactions between moisture and protein.

\section{Stability Tests of Powder Inoculation}

The aerobic bacteria counts of both types of uninoculated milk powders were estimated to be $<100$ $\mathrm{cfu} / \mathrm{g}$. As the inoculated population of Salmonella was considerably higher and differential medium (mTSA) was used for enumeration, the overall microbial results should not be affected by the background microflora. The detection limit of the enumeration method used in this study was $<10 \mathrm{cfu} / \mathrm{g}$.

The initial Salmonella populations after inoculation ranged from 7.7 to 7.9 and 8.1 to $8.5 \log \mathrm{cfu} / \mathrm{g}$, in WMP and NFDM, respectively (Figure 2). One day after the samples were transferred to the equilibration chamber,

\section{WMP}

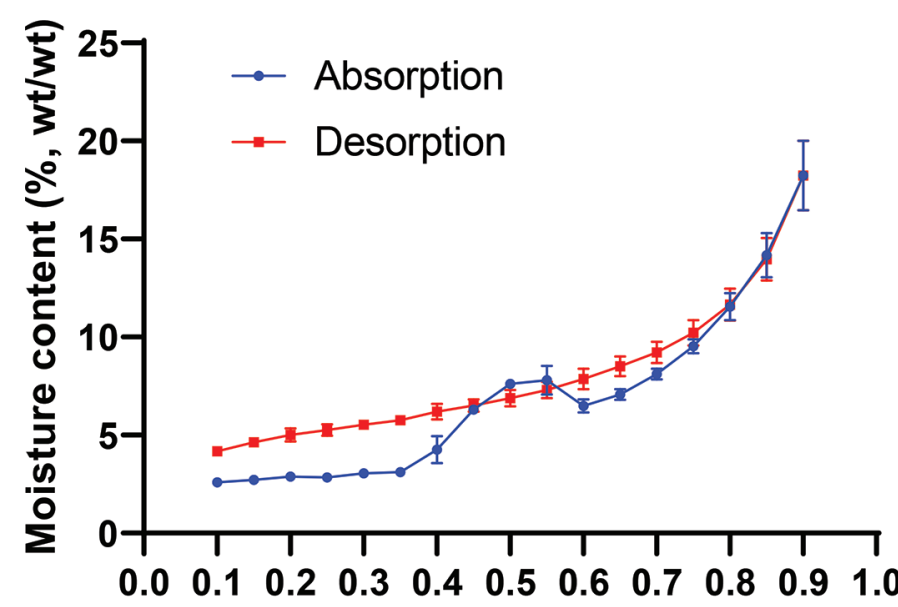

NFDM

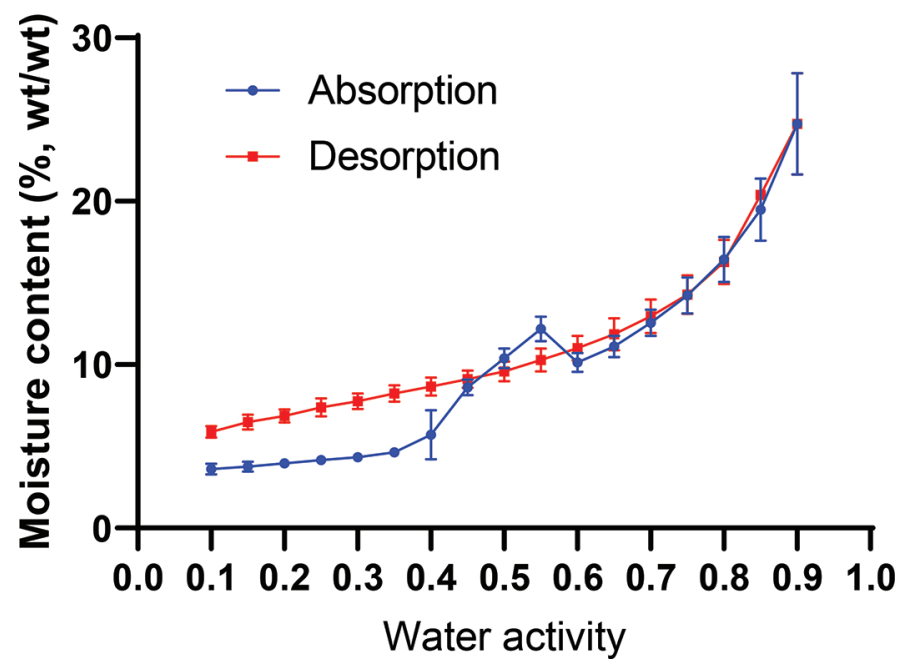

Figure 1. Moisture sorption isotherm of whole milk powder (WMP) and nonfat dry milk (NFDM) at $20^{\circ} \mathrm{C}$. The moisture content at equilibration point was determined in triplicate at a water activity $\left(\mathrm{a}_{\mathrm{w}}\right)$ level from 0.10 to 0.90 at 0.05 -unit intervals. The error bar indicates 1 SD.

the $\mathrm{a}_{\mathrm{w}}$ levels of WMP and NFDM were adjusted to the target $\mathrm{a}_{\mathrm{w}}$. About 1.1 and $0.5 \log \mathrm{cfu} / \mathrm{g}$ reductions of Salmonella in WMP and NFDM, respectively, were observed at the end of the $\mathrm{a}_{\mathrm{w}}$ adjustment (Figure 2).

Table 1. Proximate composition (\%, mean $\pm \mathrm{SD}$, unless otherwise noted) of whole milk powder $(\mathrm{WMP})$ and nonfat dry milk $(\mathrm{NFDM})$, $\mathrm{n}=3$ samples

\begin{tabular}{|c|c|c|c|c|c|c|c|}
\hline Milk powder & Ash & Protein & Lipid & Carbohydrate & Moisture & $\begin{array}{c}\text { Water } \\
\text { activity (-) }\end{array}$ & $\begin{array}{l}\text { Calories } \\
\text { (kcal/kg) }\end{array}$ \\
\hline WMP & $4.91 \pm 0.53$ & $25.50 \pm 0.12$ & $29.46 \pm 0.52$ & $37.62 \pm 1.27$ & $2.51 \pm 0.43$ & $0.175 \pm 0.001$ & $5,176.2 \pm 17.10$ \\
\hline NFDM & $7.97 \pm 0.24$ & $36.41 \pm 0.24$ & $0.62 \pm 0.03$ & $51.77 \pm 0.52$ & $3.23 \pm 0.29$ & $0.158 \pm 0.002$ & $3,583.0 \pm 14.10$ \\
\hline
\end{tabular}


The Salmonella populations in WMP and NFDM were then monitored during the following $20 \mathrm{~d}$, and a $<0.2 \log \mathrm{cfu} / \mathrm{g}$ reduction of Salmonella population was found in both samples. The inoculation method used in this study was shown to provide stable Salmonella populations in both types of milk powders prepared for thermal treatment. Different inoculation methodologies have been shown to significantly influence the thermal inactivation of Salmonella in low $\mathrm{a}_{\mathrm{w}}$ foods (Hildebrandt et al., 2016, 2017; Liu et al., 2019). A proper inoculation method that simulates the real route of sample contamination could help yield more reliable inactivation kinetics. Hildebrandt et al. (2016) suggested that a lawn-based pelletized inoculum, which was used in this study, could provide a stable Salmonella population before isothermal treatment and yield consistent $D$-values. Several studies have shown that this lawn-based inoculation method provides consistent and stable Salmonella inoculated samples of different low- $\mathrm{a}_{\mathrm{w}}$ foods, such as spices (Chen et al., 2019; Wei et al., 2018, 2019), oat and wheat flour (Liu et al., 2018; Verma et al., 2018), and egg white powder (Wei et al., 2020). Also, this wet inoculation method could simulate a common contamination scenario of milk powders, in which Salmonella-contaminated liquid drips from the roof of a processing plant into the powders being processed.

The 20-d stability tests indicated that Salmonella could survive in milk powders for a long time, and no considerable decrease in Salmonella population was found after the inoculated samples were stabilized. Several studies (Abd et al., 2012; Keller et al., 2013; Lian

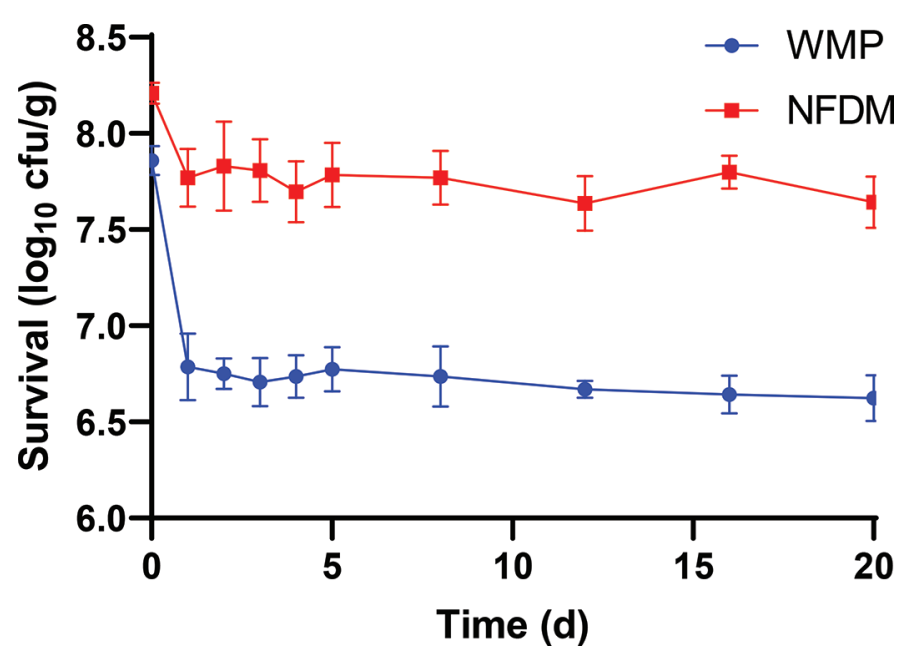

Figure 2. Stability tests of Salmonella in whole milk powder (WMP) and nonfat dry milk (NFDM). Samples from each independent batch were collected and enumerated at d $0,1,2,3,4,5,8,12$, 16 , and 20 . The error bar indicates 1 SD. et al., 2015) have shown that Salmonella could survive in low- $a_{w}$ foods for a long period, and higher survival of Salmonella was found at a lower $\mathrm{a}_{\mathrm{w}}$ level.

During the $\mathrm{a}_{\mathrm{w}}$ adjustment of milk powders and the corresponding desiccation stress, thermal resistance of Salmonella bacteria would begin to increase (Gruzdev et al., 2011). Therefore, the inoculated samples were equilibrated for at least $5 \mathrm{~d}$ before isothermal treatment to allow the inoculated Salmonella to fully adapt to the low- $\mathrm{a}_{\mathrm{w}}$ environment and presumably attain a high thermal resistance.

\section{Thermal Resistance of Salmonella in WMP and NFDM}

This study aimed to determine the effect of $\mathrm{a}_{\mathrm{w}}$ on the thermal inactivation kinetics of Salmonella in WMP and NFDM. At 75,80 , and $85^{\circ} \mathrm{C}$, WMP had comeup times of 63,74 , and 75 s, respectively. Similarly, the come-up times of NFDM were 87,87 , and $88 \mathrm{~s}$ at 75,80 , and $85^{\circ} \mathrm{C}$, respectively. The thermal-death-time sandwich has a proportional-integral-derivative (PID) control system to achieve the target temperature. When 2 standard deviations were added to the mean time to reach the target temperature, the come-up time values were similar for all isothermal temperatures. The isothermal inactivation curves of Salmonella in WMP and NFDM at $\mathrm{a}_{\mathrm{w}}$ of $0.10,0.20$, and 0.30 are shown in Figure 3.

Thermal resistance parameters of WMP and NFDM are reported in Table 2. According to Liu et al. (2019), the $D$-value of Salmonella in NFDM with $\mathrm{a}_{\mathrm{w}}$ of 0.25 at $85^{\circ} \mathrm{C}$ was $16.05 \mathrm{~min}$. Michael et al. (2014) reported that $D$-values of Salmonella in NFDM were 23.02, 10.45, 8.63 , and $5.82 \mathrm{~min}$ at $75,80,85$, and $90^{\circ} \mathrm{C}$, respectively ( $\mathrm{a}_{\mathrm{w}}$ data were not reported). In this study, at $\mathrm{a}_{\mathrm{w}}$ of 0.20 , the $D$-values of Salmonella at 75,80 , and $85^{\circ} \mathrm{C}$, respectively, were $22.70,12.11$, and $6.17 \mathrm{~min}$ for WMP and $26.76,10.46$, and 5.60 for NFDM (Table 2). The minor differences in $D$-values for similar products could be attributed to the use of different bacterial strains (Quintavalla et al., 2001; Ma et al., 2009), different inoculation methods (Bowman et al., 2015; Liu et al., 2019), or different $a_{w}$ (Villa-Rojas et al., 2013; Syamaladevi et al., 2016; Tsai et al., 2019). For both types of milk powders, at all temperatures and $\mathrm{a}_{\mathrm{w}}$ levels, the isothermal inactivation curves were found to follow a log-linear trend with high $R^{2}$ values $\left(R^{2}>0.94\right)$.

The effect of temperatures and $\mathrm{a}_{\mathrm{w}}$ on $\log _{10} D$-values are shown in Figure 4. The $z_{T}$ values of Salmonella in both milk powder at different $\mathrm{a}_{\mathrm{w}}$ levels ranged from 14.75 to $17.68^{\circ} \mathrm{C}$, and the $z_{\text {aw }}$ values ranged from 0.44 to 0.66 (Table 2). Liu et al. (2019) reported that the 
WMP, $a_{w}=0.10$
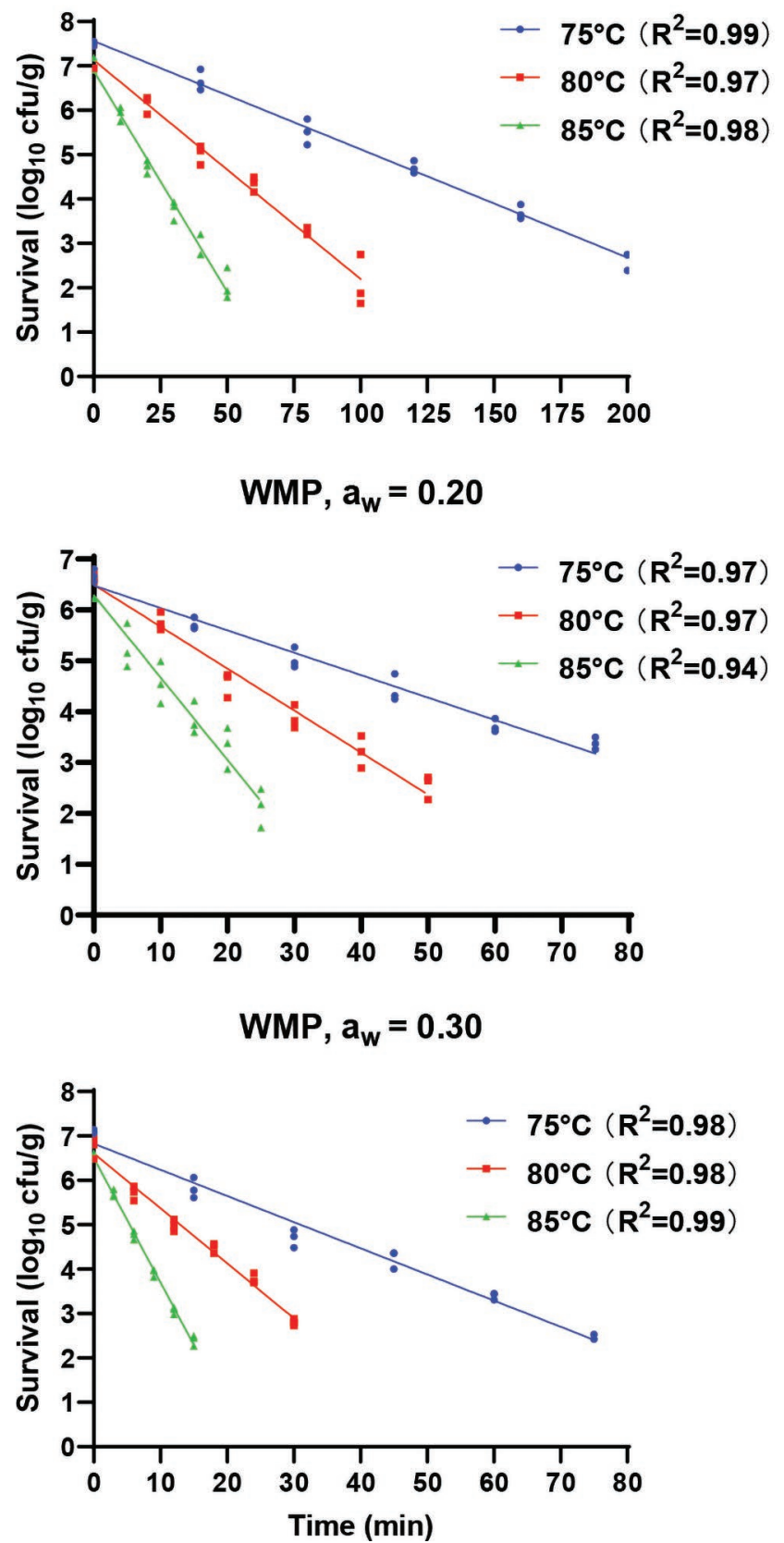

NFDM, $a_{w}=0.10$
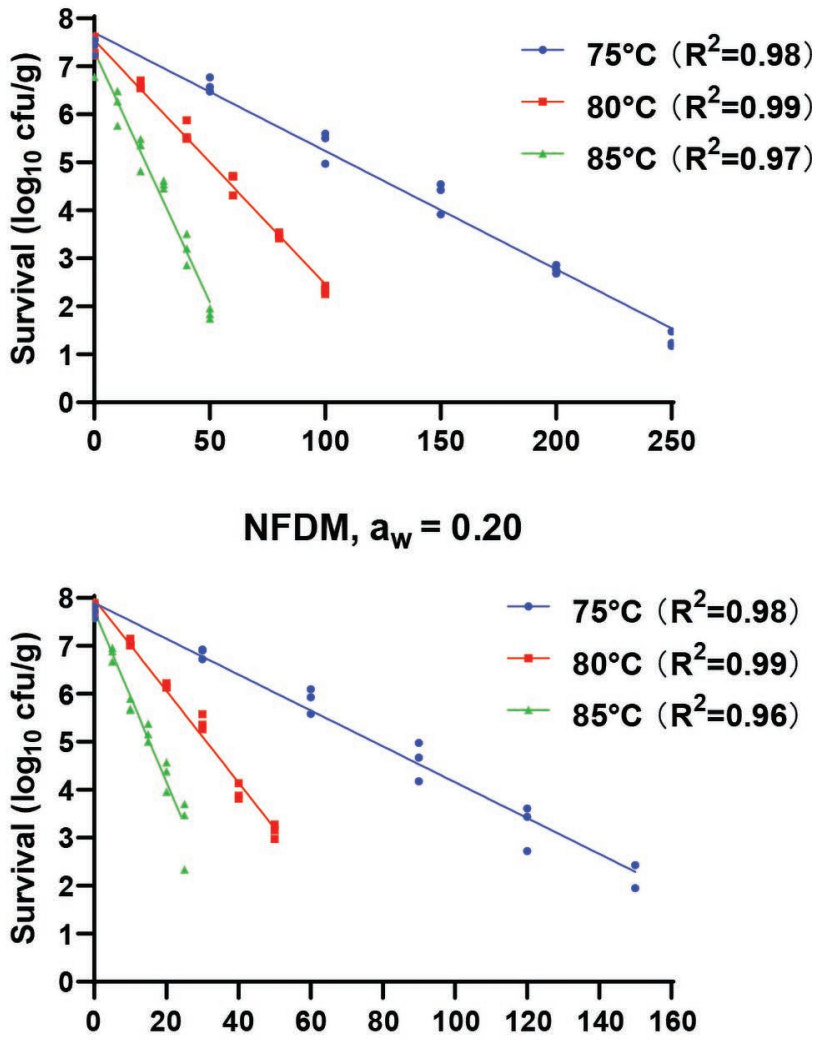

NFDM, $a_{w}=0.30$

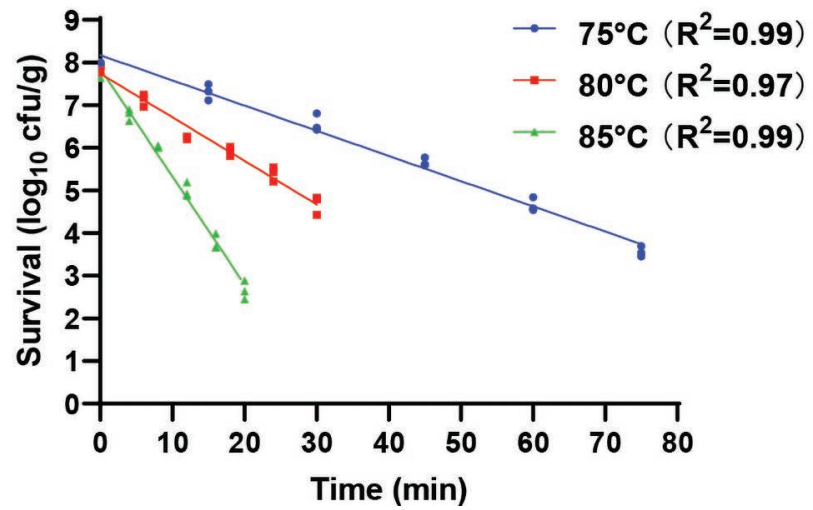

Figure 3. Thermal inactivation kinetics of Salmonella in whole milk powder (WMP) and nonfat dry milk (NFDM) equilibrated to the different water activity $\left(\mathrm{a}_{\mathrm{w}} ; 0.10,0.20\right.$ and 0.30$)$ levels at various temperatures. Each isothermal treatment condition was performed in triplicate.

$z$-values of Salmonella in NFDM at $\mathrm{a}_{\mathrm{w}}$ of 0.25 varied between 16.0 and $16.5^{\circ} \mathrm{C}$, which were similar to the $z$-values of Salmonella in NFDM found in this study. No significant difference $(P<0.05)$ was found for the $z$-values of Salmonella in NFDM at different $\mathrm{a}_{\mathrm{w}}$ levels. The estimated $z$-values could be used to predict the $D$-values at different temperatures, which could assist in determining the desired thermal processing temperature. If a food manufacturer wants to estimate a $D$-value simultaneously in water activity and temperature, these independent $z$-values will not be sufficient. Therefore, the RSM and Bigelow model were developed.

The RSM were fit for $D$-values of Salmonella in WMP and NFDM under isothermal treatment at different $\mathrm{a}_{\mathrm{w}}$ 
Table 2. Thermal resistance of Salmonella in whole milk powder (WMP) and nonfat dry milk (NFDM) at different water activities $\left(\mathrm{a}_{\mathrm{w}}\right)^{1}$

\begin{tabular}{|c|c|c|c|c|c|}
\hline Milk powder & $a_{w}$ & $\begin{array}{l}\text { Temperature } \\
\left({ }^{\circ} \mathrm{C}\right)\end{array}$ & $D$-value $(\min )$ & $\begin{array}{c}\mathrm{RMSE}^{2} \\
(\log \mathrm{cfu} / \mathrm{g})\end{array}$ & $z$-value ${ }^{3}\left({ }^{\circ} \mathrm{C}\right)$ \\
\hline \multirow[t]{3}{*}{ WMP } & 0.10 & $\begin{array}{l}75 \\
80 \\
85\end{array}$ & $\begin{array}{l}41.10 \pm 2.69^{\mathrm{a}} \\
22.83 \pm 2.51^{\mathrm{d}} \\
10.11 \pm 0.97^{\mathrm{g}}\end{array}$ & $\begin{array}{l}0.17 \\
0.27 \\
0.22\end{array}$ & $16.41 \pm 0.62^{\mathrm{ab}}$ \\
\hline & 0.20 & $\begin{array}{l}75 \\
80 \\
85\end{array}$ & $\begin{aligned} 22.79 & \pm 1.68^{\mathrm{c}} \\
12.12 & \pm 0.41^{\mathrm{f}} \\
6.17 & \pm 0.06^{\mathrm{ij}}\end{aligned}$ & $\begin{array}{l}0.20 \\
0.25 \\
0.35\end{array}$ & $17.68 \pm 0.95^{\mathrm{a}}$ \\
\hline & 0.30 & $\begin{array}{l}75 \\
80 \\
85\end{array}$ & $\begin{aligned} 16.97 & \pm 0.05^{\mathrm{e}} \\
8.11 & \pm 0.62^{\mathrm{hj}} \\
3.56 & \pm 0.10^{\mathrm{k}}\end{aligned}$ & $\begin{array}{l}0.24 \\
0.18 \\
0.10\end{array}$ & $14.75 \pm 0.26^{\mathrm{c}}$ \\
\hline \multirow[t]{3}{*}{ NFDM } & 0.10 & $\begin{array}{l}75 \\
80 \\
85\end{array}$ & $\begin{aligned} 40.58 & \pm 0.51^{\mathrm{a}} \\
19.69 & \pm 0.59^{\mathrm{d}} \\
9.63 & \pm 0.76^{\mathrm{gh}}\end{aligned}$ & $\begin{array}{l}0.28 \\
0.17 \\
0.31\end{array}$ & $16.01 \pm 0.97^{\mathrm{bc}}$ \\
\hline & 0.20 & $\begin{array}{l}75 \\
80 \\
85\end{array}$ & $\begin{aligned} 26.87 & \pm 2.09^{\mathrm{b}} \\
10.46 & \pm 0.22^{\mathrm{fg}} \\
5.65 & \pm 0.65^{\mathrm{j}}\end{aligned}$ & $\begin{array}{l}0.29 \\
0.20 \\
0.31\end{array}$ & $14.90 \pm 0.10^{\mathrm{bc}}$ \\
\hline & 0.30 & $\begin{array}{l}75 \\
80 \\
85\end{array}$ & $\begin{aligned} 16.95 & \pm 0.53^{\mathrm{e}} \\
9.82 & \pm 0.66^{\mathrm{gh}} \\
3.64 & \pm 0.48^{\mathrm{k}}\end{aligned}$ & $\begin{array}{l}0.18 \\
0.18 \\
0.18\end{array}$ & $15.02 \pm 1.45^{\mathrm{bc}}$ \\
\hline
\end{tabular}

${ }^{\mathrm{a}-\mathrm{k}}$ Within a column, values with differing letters are significantly different $(P<0.05)$.

${ }^{1}$ Values are mean $\pm \mathrm{SD}$.

${ }^{2} \mathrm{RMSE}=$ root mean square error.

${ }^{3} \mathrm{~A}$ single $\mathrm{z}$-value of each $\mathrm{a}_{\mathrm{w}}$ was determined based on the 3 temperatures.

and temperatures. The resulting $D$-value models were as follows:

For WMP:

$$
\begin{aligned}
& D=1,162.581479-24.321946 T-896.135507 a_{w} \\
& +8.788976 T a_{w}+0.128314 T^{2}+303.089547 a_{w}{ }^{2} ; \\
& R M S E=1.70 \min ; A I C_{c}=119.20 .
\end{aligned}
$$

For NFDM:

$$
\begin{aligned}
& D=1,347.962075-28.889744 T-867.512273 a_{w} \\
& +8.825606 T a_{w}+0.5587 T^{2}+239.108313 a_{w}{ }^{2} ; \\
& R M S E=1.36 \min ; A I C_{c}=107.32 .
\end{aligned}
$$

where $D=D$-values of WMP and NFDM, $T=$ isothermal treatment temperature $\left({ }^{\circ} \mathrm{C}\right)$, and $a_{w}=$ water activity of the sample.

The fitted modified Bigelow models were as follows:

$$
\begin{aligned}
& \text { WMP: } D=33.13 \cdot 10^{\frac{0.12-a_{w}}{0.54}} \cdot 10^{\frac{75.8-T}{15.4}} ; \\
& R M S E=1.57 \mathrm{~min}, A I C_{c}=31.33 ; \\
& \mathrm{NFDM}: D=32.58 \cdot 10^{\frac{0.12-a_{w}}{0.47}} \cdot 10^{\frac{75.7-T}{16.65}} ; \\
& R M S E=1.25 \mathrm{~min}, A I C_{c}=18.81 .
\end{aligned}
$$

For both RSM models, temperature and $\mathrm{a}_{\mathrm{w}}$ showed significant linear and quadratic effects and a significant interaction between temperature and $\mathrm{a}_{\mathrm{w}}$. In these 2 models, the estimated values of each parameter were not different from each other $(P>0.05)$. Therefore, data were combined for both milk powders and the following universal RSM and modified Bigelow model were generated for both WMP and NFDM:

$$
\begin{aligned}
& D=1,255.271777-26.605845 T-881.82389 a_{w} \\
& +8.807291 T a_{w}+0.1421 T^{2}+271.09893 a_{w}{ }^{2} ; \\
& R M S E=1.61 \mathrm{~min} ; A I C_{c}=218.43 ; \\
& D=32.58 \cdot 10^{\frac{0.12-a_{w}}{0.47}} \cdot 10^{\frac{75.7-T}{16.65}} ; \\
& R M S E=1.47 \mathrm{~min}, A I C_{c}=47.40 .
\end{aligned}
$$

The universal models also provided a reasonable prediction of $D$-values for both types of milk powders and may be more convenient for use as a reference for the food industry. The predictions and residual analyses of both models are shown in Figure 5. In general, the RMSE of both models are within an acceptable range. However, for the predictions of lower D-values (at the higher temperature and $\mathrm{a}_{\mathrm{w}}$ ), the residuals indicate high percent errors with up to $\pm 41.8 \%$ for RSM and $\pm 24.0 \%$ for the modified Bigelow model. The fat content did not have a significant effect on the $D$-values of the 
WMP

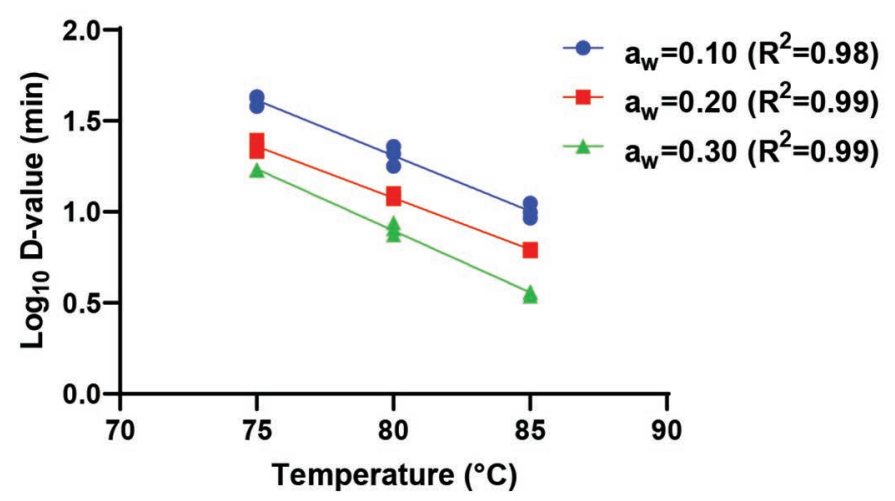

WMP

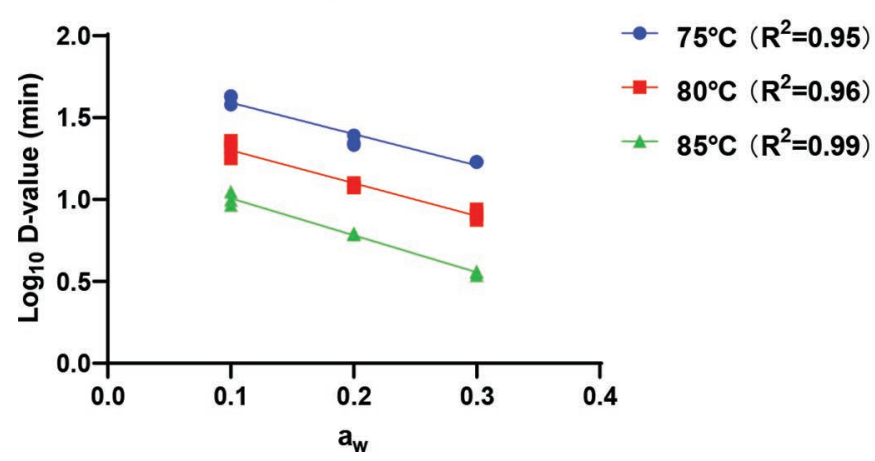

NFDM

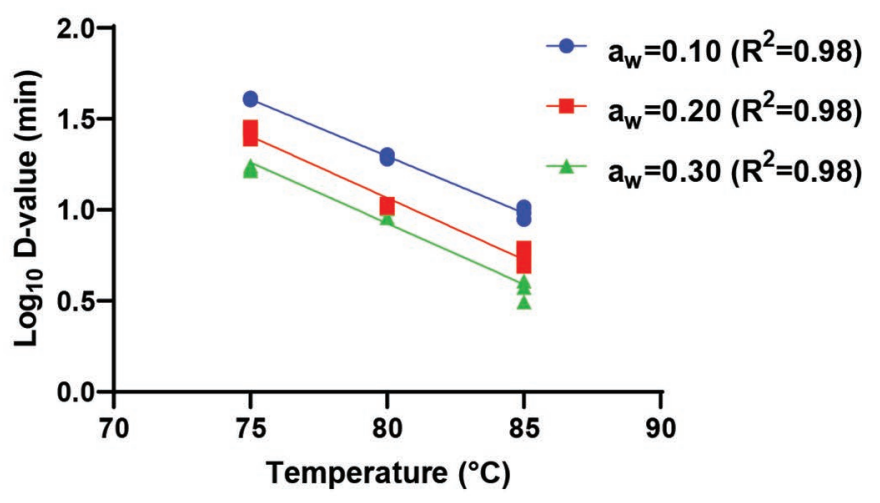

NFDM

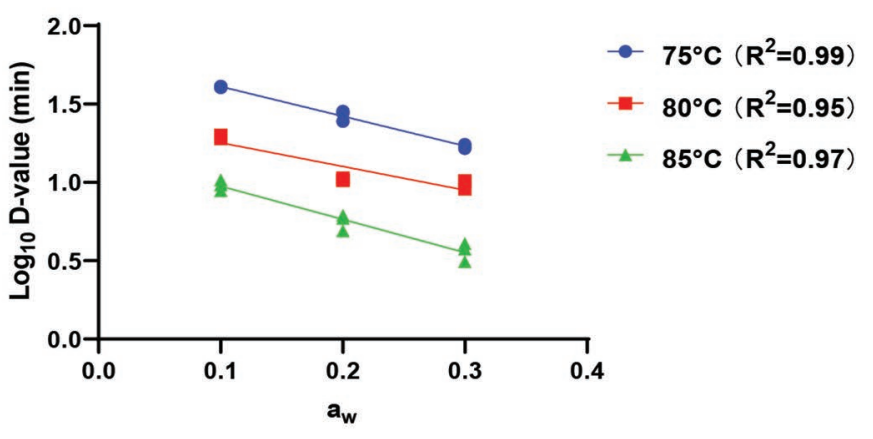

Figure 4. The $z$-values for temperature (top) and water activity $\left(\mathrm{a}_{\mathrm{w}}\right.$; bottom) of Salmonella in whole milk powder (WMP) and nonfat dry milk (NFDM).

RSM and therefore was not included in the final model. Although the protective effect of fat on Salmonella inactivation has been observed in many high-moisture foods (Ahmed et al., 1995; Verma et al., 2018), a similar protective effect was not found in milk powders. A protective effect of fat was not observed in milk powder during this short storage time $(5 \mathrm{~d})$.

For the convenience of application of the RSM, an RSM to directly predict log reductions was generated by including time $(t)$ as an independent variable as follows for both WMP and NFDM:

$$
\begin{aligned}
\log \left(N_{o} / N\right)= & 106.5685-2.585471 T-57.91383 a_{w} \\
& -0.6847655 t+0.7147467 a_{w}+0.008980569 T t \\
& +0.2262141 a_{w} t+0.01567976 T^{2}+6.369736 a_{w}{ }^{2} \\
& +0.00004763879 t^{2} ; \\
R M S E & =0.48 \log \mathrm{cfu} / \mathrm{g}, \text { AIC }_{c}=617.19 ;
\end{aligned}
$$

where $\log \left(N_{o} / N\right)$ is the log reduction of Salmonella in WMP and NFDM, and $t$ is the holding time of isothermal treatment. This model could predict Salmonella reduction directly for both types of milk powders, which is more convenient for industrial applications. To compare its performance with the combined Bigelow model, the log reduction could also be predicted by using $D$ values generated from the universal Bigelow model, which gave an RMSE of $0.47 \mathrm{log} \mathrm{cfu} / \mathrm{g}$ and $\mathrm{AIC}_{\mathrm{c}}$ of -456.93 . The predictions and residual analyses of both models are shown in Figure 6.

Based on the $\mathrm{AIC}_{\mathrm{c}}$ and RMSE values, the modified Bigelow model was a better fit for the range of conditions evaluated than the RSM, which agreed with Smith et al. (2016). Although the RSM is an empirical (data-driven) model, the Bigelow model is a mechanistic model with phenomenological meaning and is preferable.

\section{Influence of Temperature and $a_{w}$ on the Thermal Resistance of Salmonella}

The contour plots based on the developed universal model for predicting $D$-values are shown in Figure 7. According to the results, temperature had a significant positive effect $(P<0.05)$ on the inactivation of Salmo- 
nella in both milk powders. A significant negative effect $(P<0.05)$ of $\mathrm{a}_{\mathrm{w}}$ was observed on the inactivation of Salmonella in both milk powders based on the models. Therefore, a higher temperature would be required to obtain similar inactivation kinetics at lower $\mathrm{a}_{\mathrm{w}}$ levels, supporting the observation that Salmonella thermal resistance increases at lower $\mathrm{a}_{\mathrm{w}}$ values.

During the thermal processing of low- $\mathrm{a}_{\mathrm{w}}$ foods, $\mathrm{a}_{\mathrm{w}}$ is a critical parameter to be controlled because it considerably affects the heat resistance of bacteria (Aljarallah and Adams, 2007; Podolak et al., 2010). Low $\mathrm{a}_{\mathrm{w}}$ has been reported to have a protective effect on different foodborne pathogens, such as Staphylococcus epidermidis (Verrips and Van Rhee, 1981), Listeria monocytogenes (Valdramidis et al., 2006), and Salmonella enterica (Villa-Rojas et al., 2013; Smith et al., 2016). In this study, D-values of Salmonella in both WMP and NFDM increased with decreasing $a_{w}$, which indicated that a longer thermal treatment time would be required to achieve the desired reduction of Salmonella for the milk powder with lower $\mathrm{a}_{\mathrm{w}}$.

Because of moisture evaporation during thermal processing, the $\mathrm{a}_{\mathrm{w}}$ of milk powder is expected to decrease throughout thermal pasteurization. The reduced $a_{w}$
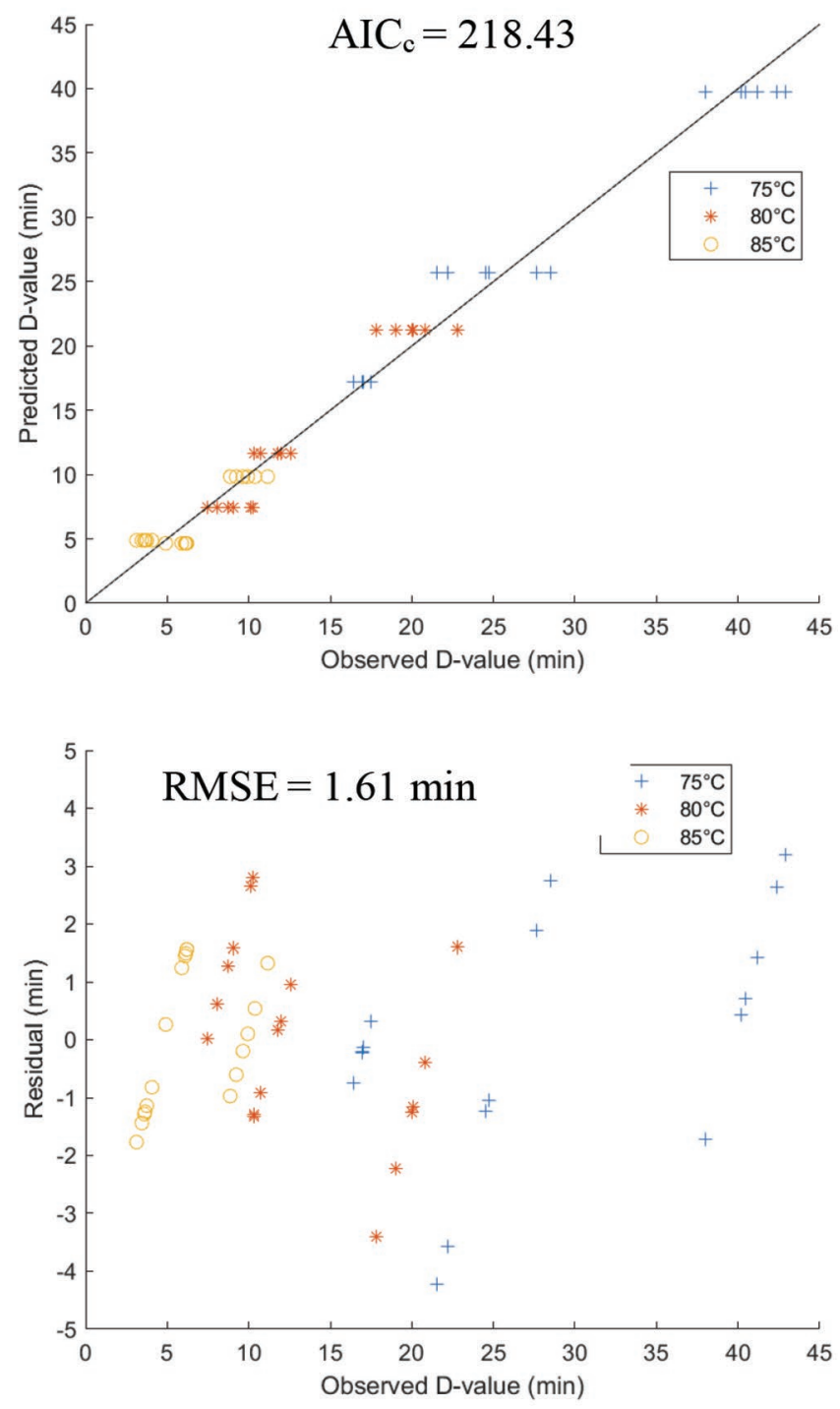

RSM
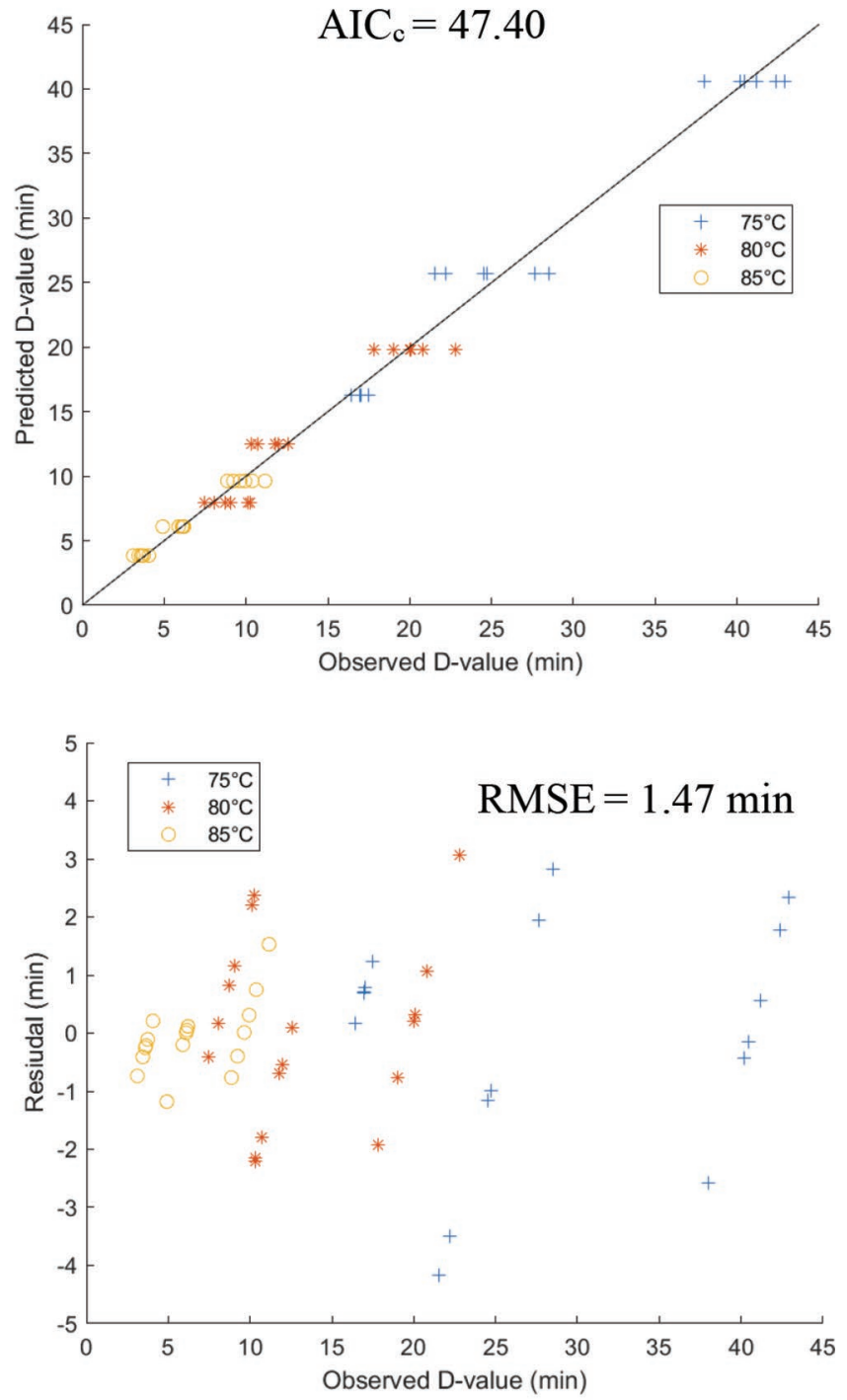

Bigelow

Figure 5. Comparison of the response surface model (RSM) and modified Bigelow model for predicting D-value of Salmonella in milk powders. AICc $=$ corrected Akaike information criterion; RMSE $=$ root mean square error 
could enhance the thermal resistance of Salmonella, which will thus require a more severe treatment. It is essential to understand the effect of $\mathrm{a}_{\mathrm{w}}$ on thermal inactivation of Salmonella in milk powders when developing the proper pasteurization process. The models developed in this study will help the food industry to understand the effects of temperature and $\mathrm{a}_{\mathrm{w}}$ on the thermal inactivation of Salmonella in milk powders and to identify the proper temperature-time combinations for the development and implementation of pasteurization process to ensure food safety.

\section{CONCLUSIONS}

The inoculation method used in this study achieved high and stable populations of Salmonella in both WMP and NFDM. The thermal resistance of Salmonella has been shown to increase significantly with decreasing $\mathrm{a}_{\mathrm{w}}$. However, different fat contents in WMP and NFDM did not significantly affect the thermal resistance of Salmonella. The universal models developed here could be a valuable tool to predict a reference $D$-value of Salmonella at selected $\mathrm{a}_{\mathrm{w}}$ and temperature values for
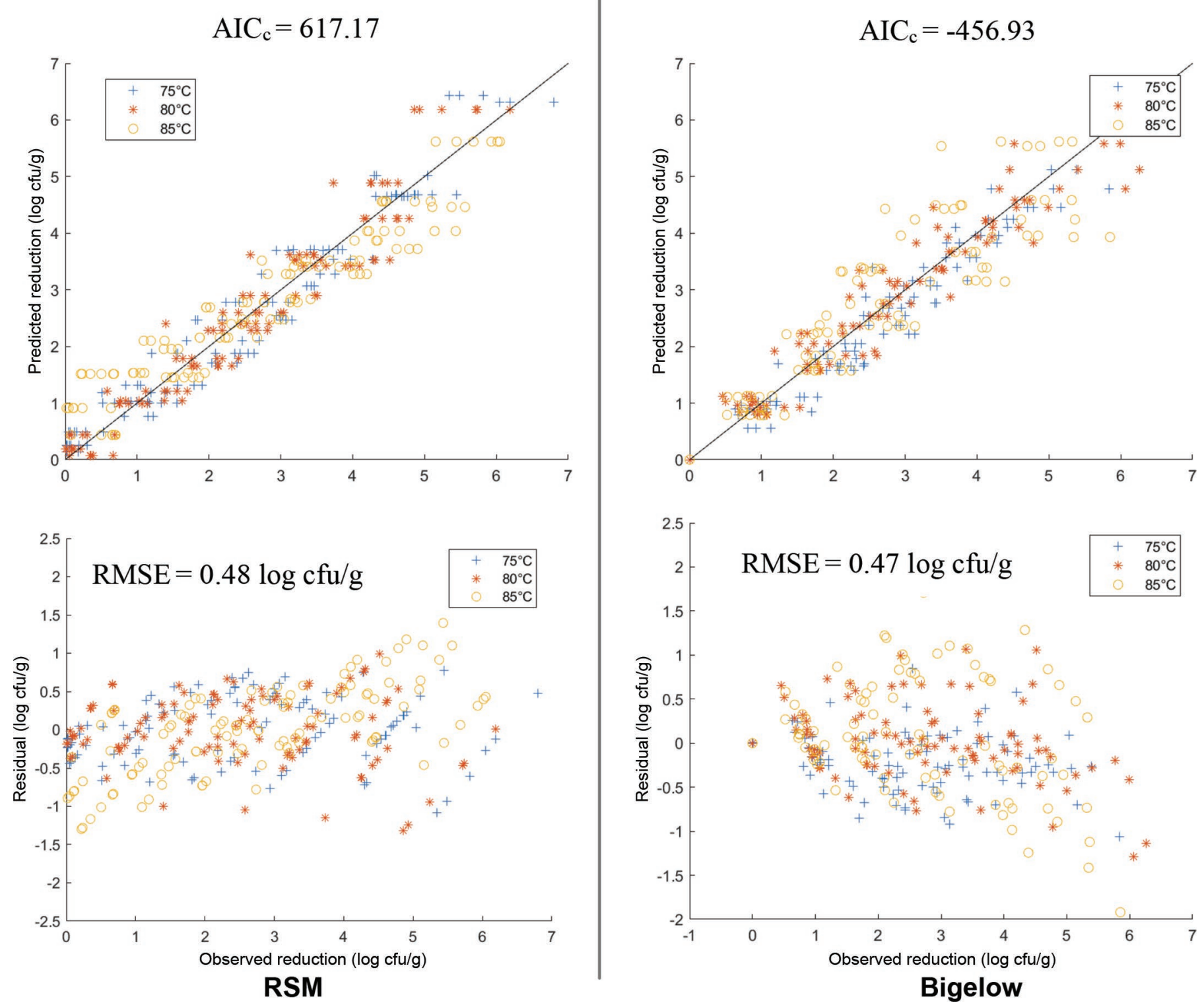

Figure 6. Comparison of response surface model (RSM) for predicting log reduction and modified Bigelow model for predicting $D$-values by evaluating $\log$ reductions of Salmonella in milk powders. AICc = corrected Akaike information criterion; RMSE $=$ root mean square error. 


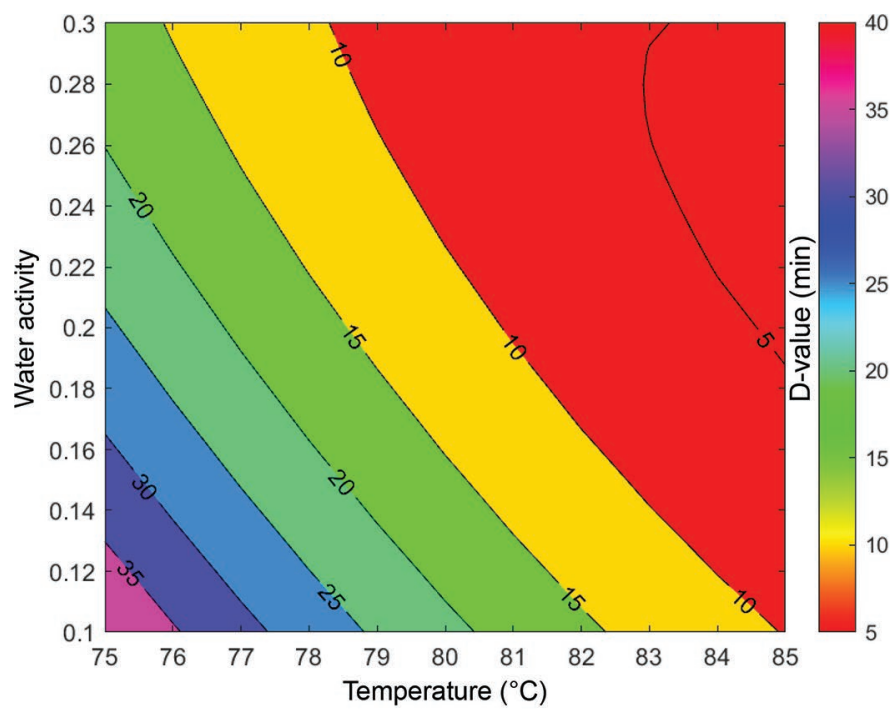

RSM

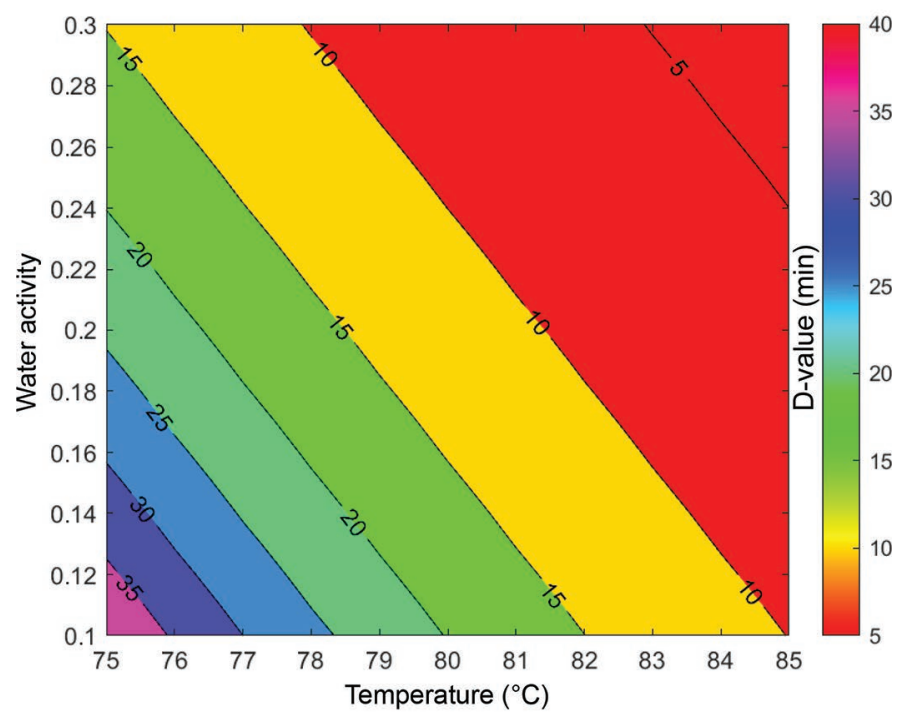

Modified Bigelow model

Figure 7. Contour surface plots of predicted $D$-values $(\min )$ of Salmonella in both types of milk powders as a function of temperature and water activity $\left(\mathrm{a}_{\mathrm{w}}\right)$ by the response surface model (RSM) and modified Bigelow model.

the food industry. The thermal inactivation kinetics of Salmonella in milk powders could provide technical information for developing and validating thermal processing to control Salmonella in milk powders.

\section{ACKNOWLEDGMENTS}

This project was funded by the National Dairy Council (Rosemont, IL) and Mars Wrigley (Chicago,
IL). The milk powder samples were provided by Mars Wrigley. The author have not stated any conflicts of interest.

\section{REFERENCES}

Abd, S. J., K. L. McCarthy, and L. J. Harris. 2012. Impact of storage time and temperature on thermal inactivation of Salmonella Enteritidis PT 30 on oil-roasted almonds. J. Food Sci. 77:M42-M47. https://doi.org/10.1111/j.1750-3841.2011.02439.x.

Ahmed, N. M., D. E. Conner, and D. L. Huffman. 1995. Heat-resistance of Escherichia coli O157:H7 in meat and poultry as affected by product composition. J. Food Sci. 60:606-610. https://doi.org/ 10.1111/j.1365-2621.1995.tb09838.x.

Aljarallah, K. M., and M. R. Adams. 2007. Mechanisms of heat inactivation in Salmonella serotype Typhimurium as affected by low water activity at different temperatures. J. Appl. Microbiol. 102:153-160. https://doi.org/10.1111/j.1365-2672.2006.03054.x.

Angulo, F. J., S. M. Cahill, I. K. Wachsmuth, M. de L. Costarrica, and P. K. B. Embarek. 2008. Powdered infant formula as a source of Salmonella infection in infants. Clin. Infect. Dis. 46:268-273. https: //doi.org/10.1086/524737.

AOAC International. 2000. Official Methods of Analysis. 17th ed. AOAC International, Gaithersburg, MD.

Berggren, J., and G. Alderborn. 2004. Long-term stabilisation potential of poly (vinylpyrrolidone) for amorphous lactose in spray-dried composites. Eur. J. Pharm. Sci. 21:209-215. https://doi.org/10 .1016/j.ejps.2003.10.005.

Blessington, T., C. G. Theofel, and L. J. Harris. 2013. A dry-inoculation method for nut kernels. Food Microbiol. 33:292-297. https:// doi.org/10.1016/j.fm.2012.09.009.

Bowman, L. S., K. M. Waterman, R. C. Williams, and M. A. Ponder. 2015. Inoculation preparation affects survival of Salmonella enterica on whole black peppercorns and cumin seeds stored at low water activity. J. Food Prot. 78:1259-1265. https://doi.org/10 .4315/0362-028X.JFP-14-483.

Brouard, C., E. Espié, F.-X. Weill, A. Kérouanton, A. Brisabois, A.M. Forgue, V. Vaillant, and H. de Valk. 2007. Two consecutive large outbreaks of Salmonella enterica serotype Agona infections in infants linked to the consumption of powdered infant formula. Pediatr. Infect. Dis. J. 26:148-152. https://doi.org/10.1097/01.inf .0000253219 .06258 .23 .

CDC (Centers for Disease Control and Prevention . 1993. Salmonella serotype Tennessee in powdered milk products and infant formulaCanada and United States, 1993. Accessed April 27, 2020. https:// www.cdc.gov/mmwr/preview/mmwrhtml/00021081.htm.

Chen, L., X. Wei, S. Irmak, B. D. Chaves, and J. Subbiah. 2019. Inactivation of Salmonella enterica and Enterococcus faecium NRRL B-2354 in cumin seeds by radiofrequency heating. Food Control 103:59-69. https://doi.org/10.1016/j.foodcont.2019.04.004.

Dolan, K. D., V. P. Valdramidis, and D. K. Mishra. 2013. Parameter estimation for dynamic microbial inactivation: Which model, which precision? Food Control 29:401-408. https://doi.org/10 .1016/j.foodcont.2012.05.042.

el-Gazzar, F. E., and E. H. Marth. 1992. Salmonellae, salmonellosis, and dairy foods: A review. J. Dairy Sci. 75:2327-2343. https://doi .org/10.3168/jds.S0022-0302(92)77993-4.

Gaillard, S., I. Leguerinel, and P. Mafart. 1998. Model for combined effects of temperature, $\mathrm{pH}$ and water activity on thermal inactivation of Bacillus cereus spores. J. Food Sci. 63:887-889. https://doi .org/10.1111/j.1365-2621.1998.tb17920.x.

Garbalińska, H., M. Bochenek, W. Malorny, and J. von Werder. 2017. Comparative analysis of the dynamic vapor sorption (DVS) technique and the traditional method for sorption isotherms determination-Exemplified at autoclaved aerated concrete samples of four density classes. Cement Concr. Res. 91:97-105. https://doi .org/10.1016/j.cemconres.2016.11.001.

Gruzdev, N., R. Pinto, and S. Sela. 2011. Effect of desiccation on tolerance of Salmonella enterica to multiple stresses. Appl. Environ. Microbiol. 77:1667-1673. https://doi.org/10.1128/AEM.02156-10. 
Hartmann, M., and S. Palzer. 2011. Caking of amorphous powdersMaterial aspects, modelling and applications. Powder Technol. 206:112-121. https://doi.org/10.1016/j.powtec.2010.04.014.

Hildebrandt, I. M., C. Hu, E. M. Grasso-Kelley, P. Ye, N. M. Anderson, and S. E. Keller. 2017. Dry transfer inoculation of lowmoisture spices containing antimicrobial compounds. J. Food Prot. 80:338-344. https://doi.org/10.4315/0362-028X.JFP-16-279.

Hildebrandt, I. M., B. P. Marks, E. T. Ryser, R. Villa-Rojas, J. Tang, F. J. Garces-Vega, and S. E. Buchholz. 2016. Effects of inoculation procedures on variability and repeatability of Salmonella thermal resistance in wheat flour. J. Food Prot. 79:1833-1839. https://doi .org/10.4315/0362-028X.JFP-16-057.

Hutson, G. 2017. How to improve process control to ensure dairy product standardization. Accessed Mar. 24, 2019. https://www .dairyfoods.com/articles/92213-how-to-improve-process-control-to -ensure-dairy-product-standardization.

Ibach, A., and M. Kind. 2007. Crystallization kinetics of amorphous lactose, whey-permeate and whey powders. Carbohydr. Res. 342:1357-1365. https://doi.org/10.1016/j.carres.2007.03.002.

Johnson, N. B., L. D. Hayes, K. Brown, E. C. Hoo, K. A. Ethier, and Centers for Disease Control and Prevention (CDC). 2014. CDC National Health Report: Leading causes of morbidity and mortality and associated behavioral risk and protective factors-United States, 2005-2013. MMWR Suppl. 63:3-27.

Jourdan-da Silva, N., L. Fabre, E. Robinson, N. Fournet, A. Nisavanh, M. Bruyand, A. Mailles, E. Serre, M. Ravel, V. Guibert, S. Issenhuth-Jeanjean, C. Renaudat, M. Tourdjman, A. Septfons, H. de Valk, and S. Le Hello. 2018. Ongoing nationwide outbreak of Salmonella Agona associated with internationally distributed infant milk products, France, December 2017. Euro Surveill. 23. https://doi.org/10.2807/1560-7917.ES.2018.23.2.17-00852.

Keller, S. E., J. M. VanDoren, E. M. Grasso, and L. A. Halik. 2013. Growth and survival of Salmonella in ground black pepper (Piper nigrum). Food Microbiol. 34:182-188. https://doi.org/10.1016/j .fm.2012.12.002.

Lau, S. K., X. Wei, and J. Subbiah. 2019. Performance of an improved thermal death time sandwich system for determining the thermal death kinetics of Salmonella. Page 1-09 in IAFP Annual Meeting. Louisville, Kentucky 2019. International Association for Food Protection, Des Moines, IA.

Lenth, R. V. 2009. Response-surface methods in R, using rsm. J. Stat. Softw. 32:1-17. https://doi.org/10.18637/jss.v032.i07.

Lian, F., W. Zhao, R. Yang, Y. Tang, and W. Katiyo. 2015. Survival of Salmonella enteric in skim milk powder with different water activity and water mobility. Food Control 47:1-6. https://doi.org/ 10.1016/j.foodcont.2014.06.036.

LiCari, J. J., and N. N. Potter. 1970. Salmonella survival during spray drying and subsequent handling of skimmilk powder. II. Effects of drying conditions. J. Dairy Sci. 53:871-876. https://doi.org/10 .3168/jds.S0022-0302(70)86310-X.

Liu, S., S. Ozturk, J. Xu, F. Kong, P. Gray, M. Zhu, S. S. Sablani, and J. Tang. 2018. Microbial validation of radio frequency pasteurization of wheat flour by inoculated pack studies. J. Food Eng. 217:68-74.

Liu, S., J. Xu, L. Xie, M.-J. Zhu, and J. Tang. 2019. Dry inoculation methods for nonfat milk powder. J. Dairy Sci. 102:77-86. https:// doi.org/10.3168/jds.2018-14478.

Ma, L., G. Zhang, P. Gerner-Smidt, V. Mantripragada, I. Ezeoke, and M. P. Doyle. 2009. Thermal inactivation of Salmonella in peanut butter. J. Food Prot. 72:1596-1601. https://doi.org/10.4315/0362 -028X-72.8.1596.

McCarthy, N. A., V. L. Gee, D. K. Hickey, A. L. Kelly, J. A. O’Mahony, and M. A. Fenelon. 2013. Effect of protein content on the physical stability and microstructure of a model infant formula. Int. Dairy J. 29:53-59. https://doi.org/10.1016/j.idairyj.2012.10.004.

Michael, M., R. K. Phebus, H. Thippareddi, J. Subbiah, S. L. Birla, and K. A. Schmidt. 2014. Validation of radio-frequency dielectric heating system for destruction of Cronobacter sakazakii and Salmonella species in nonfat dry milk. J. Dairy Sci. 97:7316-7324. https://doi.org/10.3168/jds.2013-7862.
Motulsky, H., and A. Christopoulos. 2004. Fitting Models to Biological Data using Linear and Nonlinear Regression. GraphPad Software., San Diego, CA.

Park, J. K., W. S. Seok, B. J. Choi, H. M. Kim, B. K. Lim, S. S. Yoon, S. Kim, Y. S. Kim, and J. Y. Park. 2004. Salmonella enterica serovar London infections associated with consumption of infant formula. Yonsei Med. J. 45:43-48. https://doi.org/10.3349/ ymj.2004.45.1.43.

Podolak, R., E. Enache, W. Stone, D. G. Black, and P. H. Elliott. 2010. Sources and risk factors for contamination, survival, persistence, and heat resistance of Salmonella in low-moisture foods. J. Food Prot. 73:1919-1936. https://doi.org/10.4315/0362-028X-73 .10 .1919 .

Quintavalla, S., S. Larini, P. Mutti, and S. Barbuti. 2001. Evaluation of the thermal resistance of different Salmonella serotypes in pork meat containing curing additives. Int. J. Food Microbiol. 67:107114. https://doi.org/10.1016/S0168-1605(01)00430-5.

Reij, M. W., and E. D. Den Aantrekker. 2004. Recontamination as a source of pathogens in processed foods. Int. J. Food Microbiol. 91:1-11. https://doi.org/10.1016/S0168-1605(03)00295-2.

Rodríguez-Urrego, J., S. Herrera-León, A. Echeita-Sarriondia, P. Soler, F. Simon, and S. Mateo. 2010. Nationwide outbreak of Salmonella serotype Kedougou associated with infant formula, Spain, 2008. Euro Surveill. 15:19582.

Rowe, B., D. N. Hutchinson, R. J. Gilbert, B. H. Hales, N. T. Begg, H. C. Dawkins, M. Jacob, F. A. Rae, and M. Jepson. 1987. Salmonella Ealing infections associated with consumption of infant dried milk. Lancet 330:900-903. https://doi.org/10.1016/S0140 $-6736(87) 91384-5$

Shrestha, A. K., T. Howes, B. P. Adhikari, B. J. Wood, and B. R. Bhandari. 2007. Effect of protein concentration on the surface composition, water sorption and glass transition temperature of spray-dried skim milk powders. Food Chem. 104:1436-1444. https: //doi.org/10.1016/j.foodchem.2007.02.015.

Smith, D. F., I. M. Hildebrandt, K. E. Casulli, K. D. Dolan, and B. P. Marks. 2016. Modeling the effect of temperature and water activity on the thermal resistance of Salmonella Enteritidis PT 30 in wheat flour. J. Food Prot. 79:2058-2065. https://doi.org/10.4315/ 0362-028X.JFP-16-155.

Syamaladevi, R. M., R. K. Tadapaneni, J. Xu, R. Villa-Rojas, J. Tang, B. Carter, S. Sablani, and B. Marks. 2016. Water activity change at elevated temperatures and thermal resistance of Salmonella in all purpose wheat flour and peanut butter. Food Res. Int. 81:163170. https://doi.org/10.1016/j.foodres.2016.01.008.

Tham, T. W. Y., C. Wang, A. T. H. Yeoh, and W. Zhou. 2016. Moisture sorption isotherm and caking properties of infant formulas. J. Food Eng. 175:117-126. https://doi.org/10.1016/j.jfoodeng.2015 .12 .014 .

Tsai, H.-C., M. H. Taylor, X. Song, L. Sheng, J. Tang, and M.-J. Zhu. 2019. Thermal resistance of Listeria monocytogenes in natural unsweetened cocoa powder under different water activity. Food Control 102:22-28. https://doi.org/10.1016/j.foodcont.2019.03.006.

Valdramidis, V. P., A. H. Geeraerd, J. E. Gaze, A. Kondjoyan, A. R. Boyd, H. L. Shaw, and J. F. Van Impe. 2006. Quantitative description of Listeria monocytogenes inactivation kinetics with temperature and water activity as the influencing factors; model prediction and methodological validation on dynamic data. J. Food Eng. 76:79-88. https://doi.org/10.1016/j.jfoodeng.2005.05.025.

Verma, T., X. Wei, S. K. Lau, A. Bianchini, K. M. Eskridge, and J. Subbiah. 2018. Evaluation of Enterococcus faecium NRRL B-2354 as a surrogate for Salmonella during extrusion of low-moisture food. J. Food Sci. 83:1063-1072. https://doi.org/10.1111/1750 $-3841.14110$.

Verrips, C. T., and R. Van Rhee. 1981. Heat inactivation of staphylococcus epidermidis at various water activities. Appl. Environ. Microbiol. 41:1128-1131. https://doi.org/10.1128/AEM.41.5.1128 $-1131.1981$.

Villa-Rojas, R., J. Tang, S. Wang, M. Gao, D.-H. Kang, J.-H. Mah, P. Gray, M. E. Sosa-Morales, and A. Lopez-Malo. 2013. Thermal inactivation of Salmonella Enteritidis PT 30 in almond kernels as 
influenced by water activity. J. Food Prot. 76:26-32. https://doi .org/10.4315/0362-028X.JFP-11-509.

Villa-Rojas, R., M.-J. Zhu, B. P. Marks, and J. Tang. 2017. Radiofrequency inactivation of Salmonella Enteritidis PT 30 and Enterococcus faecium in wheat flour at different water activities. Biosyst. Eng. 156:7-16. https://doi.org/10.1016/j.biosystemseng.2017.01 .001 .

Wei, X., S. K. Lau, B. S. Reddy, and J. Subbiah. 2020. A microbial challenge study for validating continuous radio-frequency assisted thermal processing pasteurization of egg white powder. Food Microbiol. 85:103306. https://doi.org/10.1016/j.fm.2019.103306.

Wei, X., S. K. Lau, J. Stratton, S. Irmak, A. Bianchini, and J. Subbiah. 2018. Radio-frequency processing for inactivation of Salmonella enterica and Enterococcus faecium NRRL B-2354 in black peppercorn. J. Food Prot. 81:1685-1695. https://doi.org/10.4315/ 0362-028X.JFP-18-080.
Wei, X., S. K. Lau, J. Stratton, S. Irmak, and J. Subbiah. 2019. Radiofrequency pasteurization process for inactivation of Salmonella spp. and Enterococcus faecium NRRL B-2354 on ground black pepper. Food Microbiol. 82:388-397. https://doi.org/10.1016/j.fm 2019.03.007.

\section{ORCIDS}

Xinyao Wei @ \ttps://orcid.org/0000-0002-1746-2653

Soon Kiat Lau • https://orcid.org/0000-0001-8264-7761

Mary-Grace C. Danao (ํ) https://orcid.org/0000-0001-7898-5004

Jeyamkondan Subbiah @ https://orcid.org/0000-0002-8512-0735 